\title{
Intellectual disability health content within medical curriculum: an audit of what our future doctors are taught
}

Julian N. Trollor ${ }^{1 *}$, Beth Ruffell ${ }^{1}$, Jane Tracy ${ }^{2,3}$, Jennifer J. Torr ${ }^{2,3}$, Seeta Durvasula ${ }^{4}$, Teresa lacono ${ }^{5}$, Claire Eagleson ${ }^{1}$ and Nicolas Lennox ${ }^{6}$

\begin{abstract}
Background: There is a high burden of unmet health needs for people with intellectual disability. Despite experiencing significantly higher rates of morbidity and mortality compared with the general population, this group faces greater barriers to accessing healthcare. While increasing workplace capacity is one way to reduce this inequitable access, previous research indicates a scarcity of undergraduate teaching in intellectual disability. The aim of the study was to determine the extent and nature of intellectual disability content currently offered within medical degree curricula.

Methods: All Australian universities $(n=20)$ providing accredited medical training were invited to participate in a two-phase audit via an email invitation to the Dean of each medical school. The Dean's delegate from 14 medical schools completed Phase 1, which involved a questionnaire or telephone interview about the overall medical course structure. Unit coordinators and/or teaching staff from 12 medical schools completed Phase 2, which involved an online survey about intellectual disability content within the curriculum.

Results: In Australia, medical school curricula contain a median of $2.55 \mathrm{~h}$ of compulsory intellectual disability content. The majority of universities only offer a small amount of compulsory content. Of compulsory units, intellectual disability teaching is minimal in sexual health and emergency medicine (only one unit offered in one school for each). Topics of key relevance in intellectual disability health such as human rights issues, interdisciplinary team work and preventative health are poorly represented in intellectual disability teaching. Elective content varies markedly across universities (1 to $122 \mathrm{~h}$ ), but emergency medicine, women's health, men's health and many other specialist medicine areas are not represented. Inclusive practice is inconsistent in degree and nature, but a majority of universities (nine) involve people with intellectual disability in the development or delivery of content.
\end{abstract}

Conclusions: There is a mismatch between the considerable unmet health needs of people with intellectual disability and the inconsistent teaching within medical schools. Future doctors will be better equipped to support the health and wellbeing of people with intellectual disability if curricula are enhanced in this area.

Keywords: Intellectual Disability, Medical Education, Medical training, Curriculum, Health inequalities

\footnotetext{
* Correspondence: j.trollor@unsw.edu.au

Julian N. Trollor and Beth Ruffell as Joint first Authors.

${ }^{1}$ Department of Developmental Disability Neuropsychiatry (3DN), UNSW

Australia, 34 Botany Street, Randwick, NSW 2052, Australia

Full list of author information is available at the end of the article
} 


\section{Background}

Health needs and inequalities for people with intellectual disability

People with intellectual disability comprise approximately $1-3 \%$ of the population [1] and compared to the general population, experience significant health disadvantage and poor health outcomes [2], as evidenced by higher morbidity for physical [3] and mental [4] health conditions, and premature death from preventable causes $[5,6]$. The burden of unmet health needs in this group is high [3, 7-10], and conditions are frequently undiagnosed or inappropriately treated [11]. Despite living in the general community and being dependent on mainstream health services, people with intellectual disability continue to face disparities in access to preventive healthcare, health promotion and general healthcare [11].

The human rights of individuals with intellectual disability are protected through international agreements, including the United Nations Convention on the Rights of Persons with Disabilities (UNCRPD) [12], to which Australia became a signatory in 2007. Article 25 of this convention obliges signatory states to ensure that persons with disabilities have the right to the highest attainable standard of health without discrimination on the basis of disability. National discrimination acts such as The Equality Act 2010 [13] in the United Kingdom (UK), the Americans with Disabilities Act of 1990 [14] and the Disability Discrimination Act in Australia [15] require government and the community to take action to ensure there is no discrimination on the grounds of disability. Reasonable adjustments must therefore be made to accommodate needs, and to ensure equitable access to services. However, health service providers may lack the knowledge, skills or insights required to make such adjustments.

Initiatives to address the health needs and service gaps experienced by this group include the development of special interest clinical groups [16-21] and academic units. In Australia, the National Disability Strategy [22] has set a clear priority to obtain the highest possible health and well-being outcomes for people with disabilities through the universal equipping of health practitioners and services. Further, the National Disability Insurance Scheme [23] offers the opportunity for disability services to re-design their interface with health services and strengthen pathways to improve access for all Australians with disabilities, including intellectual disability. Similar schemes exist in the UK, with the Direct Payments and Personal Budgets scheme [24], and in Canada, with Self-Managed Care schemes [25].

\section{What are medical students taught about intellectual disability?}

Few studies have documented what student doctors are taught about intellectual disability. The results of one survey of disability and rehabilitation teaching across 23 UK medical schools, published in 1994, indicated that teaching was disjointed: there was little integration across disciplines, and few schools had clear aims [26]. Most of the content taught included medical aspects of disability and rehabilitation. Few schools included ethical aspects, or the role of support services in their curricula. In Malaysia, new medical school graduates were surveyed from seven public hospitals about the education they received on developmental disability (which includes intellectual disability) during undergraduate study [27]. The majority of respondents had studied in Malaysia (71 \%), but students who attended medical school abroad were also surveyed. It was found that lecture content in developmental disability was equally apportioned across paediatric and psychiatric curricula. Less information was received in family medicine and public health. While most respondents had contact with people with developmental disabilities while observing clinical activities (e.g. giving management advice, surgical intervention), few had the opportunity for direct clinical practice with patients with developmental disabilities. Graduates' responses also suggested that developmental disability content was less consistently taught to those trained in Eastern and Middle Eastern countries, compared with Malaysia and Western countries. Seven years after the Disability Discrimination Act [15], Lennox and Diggens [28] found major inconsistencies in Australian medical curricula in intellectual disability across universities, and highlighted gaps in relation to relevant skills and attitudes of trainees [29].

One fundamental way to address the unmet needs of people with intellectual disability is to focus on improving the intellectual disability education medical students receive. While surveys have indicated that clinicians lack confidence in the area of intellectual disability health $[30,31]$, research has demonstrated that medical training that includes intellectual disability content, especially in the form of opportunity for direct contact with people from this population (inclusive teaching), can have a positive effect on trainee confidence, competence and attitude [32-34]. Uniform provision of intellectual disability content in medical curricula is desirable as it will encourage the development of mainstream capacity of primary health care providers and their services, and will equip practitioners with much needed communication, assessment and management strategies for patients [35, 36]. This can also help to meet human rights and legislation requirements that the community takes steps to ensure no discrimination on the basis of disability $[12,15]$. Evidence suggests that tertiary education is the best time to influence the skills, knowledge, and attitudes of health professionals [37, 38]. Further, teaching in speciality areas is associated with a greater number of graduates choosing to work in those areas [39]. As specialist 
pathways in intellectual disability health and mental health are available in paediatrics and psychiatry respectively, the inclusion of intellectual disability content may encourage some to pursue this area as a speciality interest. This would provide a much needed boost to the availability of specialist health care for people with intellectual disability. Increasing the coverage of intellectual disability during undergraduate medical education could go a considerable way to addressing the unmet health needs of this population by improving workforce capacity.

The development of clinical skills in intellectual disability health has relevance beyond this specific clinical area. Apart from specific content knowledge, key skills for effective clinical practice in this area include the ability to adapt the clinical consultation to the patient's level of ability, adjust communication, work with individuals with multiple disabilities, work effectively in a multidisciplinary framework, support decision making capacities, and work with families and carers [40]. Thus teaching medical students about intellectual disability health has relevance to a much larger group of individuals including those with other developmental and acquired cognitive disorders.

Despite these findings and arguments, there is no requirement for medical programmes to include teaching content specific to intellectual disability to meet accreditation requirements [41]. This lack of requirement is also evident in other countries, such as the United States, where the standards for medical school program accreditation do not include stipulation of specific areas, such as intellectual disability, but rather refer to broader curriculum content that can apply across multiple areas (e.g. medical ethics) [42].

\section{The current study}

Despite previous research demonstrating a paucity of undergraduate medical teaching in intellectual disability
$[26,28,29]$, the current status of medical curricula is not known. We conducted a national audit of medical curricula across Australian medical schools to assess content in relation to intellectual disability. The current project is the first of a multistage strategy to build capacity within the health workforce in Australia by renewing the medical and nursing intellectual disability curriculum. In turn, it is also hoped that this research can inform development of the health workforce internationally.

\section{Methods}

A two phase national audit of medical curricula content was conducted in 2013-14. Figure 1 shows details of the recruitment and data collection procedures. The Deans of the 20 medical schools that deliver Australian Medical Council (AMC) accredited medical degrees in Australia were approached via email and invited to participate. Permission to participate was granted by fourteen medical schools. The Dean's representative then completed an interview on the medical course structure and identified potential course components where intellectual disability may reside, and the relevant coordinators of these course units (Phase 1). An email was then sent to each identified coordinator to complete a survey regarding the content of the unit(s) (Phase 2). Survey responses for Phase 2 were obtained from twelve 'participating medical schools' and this formed the basis of the results for the current study (two schools did not respond to the Phase 2 request). All participants read a participant information sheet before taking part and completion of the interview or survey was taken as implied consent. A protocol of three email reminders and a telephone call was followed at each phase. Institutions were coded to preserve anonymity during data analysis and reporting.

For enhanced comparability of audit results, the majority of questions were the same as those used by

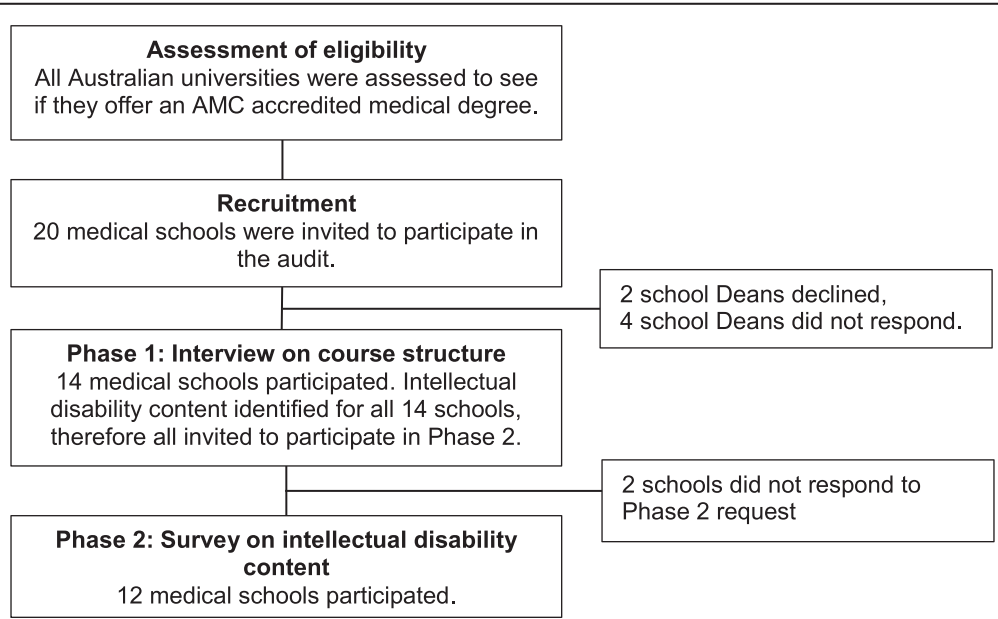

Fig. 1 Recruitment and participation rates 
Lennox and Diggens [28]. However, we included additional questions to obtain more detail regarding broad categories, discipline and topic areas of medicine covered by intellectual disability content. See Table 1 for details of question domains and categories. In Phase 1, 11 interview questions on course structure were answered over the telephone or completed on written proforma and returned by email (see Additional file 1). In Phase 2, 16 questions on specific intellectual disability content were answered via an online survey (see Additional file 2 for detailed survey tool). Ethical approval for the study was obtained from the UNSW Australia Human Research Ethics Advisory Panel (Approval No. 2013-7-03).

\section{Results}

\section{Course programmes and length}

Of the twelve medical schools that participated in Phase 2, eleven offered a Bachelor of Medicine, Bachelor of Surgery (MBBS) and one a Doctor of Medicine (MD) programme. Five participating schools offered undergraduate entry only, five offered graduate entry only, and two offered both entry pathways. Six schools offered a 4-year course, two offered a 5-year course, and four offered a 6-year course. The number of students enrolled varied across institutions $($ range $=99-520$, median $=182$ ).

\section{Intellectual disability units}

'Intellectual disability units' refers to discrete course components containing some auditable content specific to intellectual disability.

\section{Compulsory units}

The number of compulsory intellectual disability units offered across participating medical schools is presented in Fig. 2. As shown, the 12 participating schools provided a total of 42 compulsory intellectual disability units. A small number of medical schools (3 schools, $25 \%)$ provided the majority of units (27 units, $64 \%$ ). The total time dedicated to teaching intellectual disability content varied (range $=30 \mathrm{~min}-18 \mathrm{~h}$, median $=$ $2.55 \mathrm{~h}$ ). Seven participating schools $(60 \%)$ provided less than a total of six hours of teaching time on intellectual disability.

\section{Elective units}

Six participating medical schools offered a total of eight elective intellectual disability units (range $=1-3$, median $=$ 1). The number of students enrolled in these elective units varied (range $=3-180$, median $=12.5$ ), the total time spent teaching intellectual disability content in elective units ranged from 1 to $222 \mathrm{~h}$ (median $=3 \mathrm{~h}$ ). A single unit offered by one participating school included $222 \mathrm{~h}$ of intellectual disability content, with eight students ( $2 \%$ of the student population) enrolled in 2013/14.

Distribution of intellectual disability units and enrolment Intellectual disability content was unevenly distributed across years of study (Fig. 3), with more units offered in the third year than any other year.

\section{Compulsory intellectual disability content Broad categories}

Nine medical schools provided compulsory intellectual disability content that included both physical and mental health. Two schools provided compulsory content that covered only physical health, while one provided compulsory content that covered only mental health.

\section{Discipline areas}

Table 2 provides details about the discipline areas covered within compulsory intellectual disability units. Those most consistently covered included paediatrics, general practice and psychiatry, and those least covered included emergency medicine and sexual health.

\section{Specific topic areas}

Table 2 also provides details of specific topic areas included within compulsory intellectual disability units. Those most consistently covered included clinical assessment and management skills, and those least covered included human rights, and disability and health care systems.

Table 1 Question domains and categories within domains

\begin{tabular}{|c|c|c|}
\hline & Domain & Question category \\
\hline \multirow[t]{2}{*}{ Phase 1} & Course structure & $\begin{array}{l}\text { Program type; total units; entry level; duration; number of students; contact hours; number of compulsory } \\
\text { units; number of elective units; number of units containing intellectual disability specific content. }\end{array}$ \\
\hline & School staff profile & $\begin{array}{l}\text { Total number of staff specialising in intellectual disability; total number staff with a demonstrated interest } \\
\text { in intellectual disability; total number of staff who teach intellectual disability content. }\end{array}$ \\
\hline \multirow[t]{4}{*}{ Phase 2} & Unit details & Year of course; compulsory or elective enrolment; total number of students enrolled. \\
\hline & Intellectual disability content & $\begin{array}{l}\text { Total intellectual disability teaching time; type of intellectual disability content; topics covered; subject area } \\
\text { of medicine; direct clinical contact. }\end{array}$ \\
\hline & Teaching style & $\begin{array}{l}\text { Teaching mode; inclusion of people with intellectual disability in the development or delivery of content; } \\
\text { assessments; learning style. }\end{array}$ \\
\hline & Teaching staff profile & Professional background; university staff, conjoint or external employment. \\
\hline
\end{tabular}




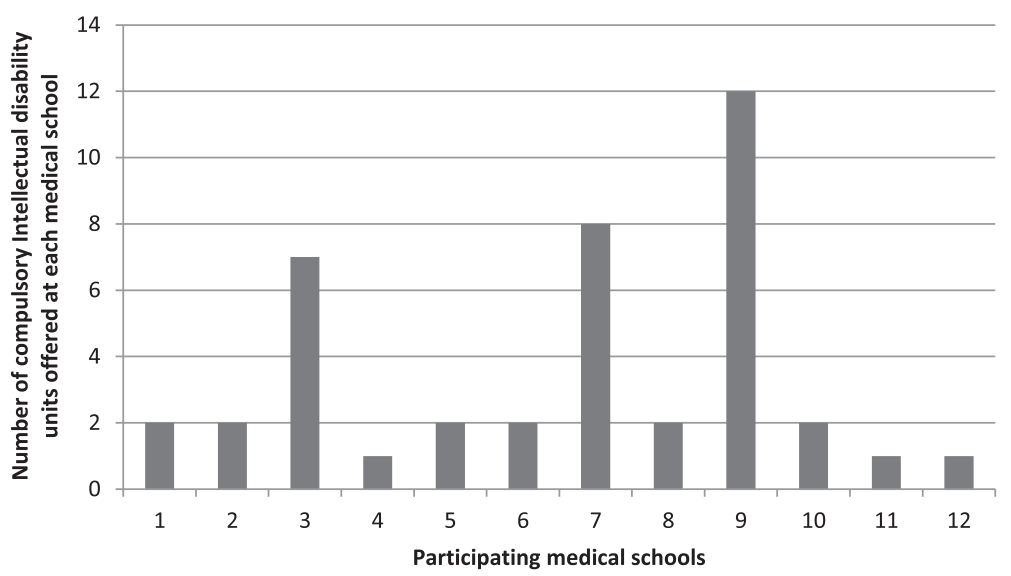

Fig. 2 Total number of compulsory intellectual disability units offered by participating universities

\section{Elective intellectual disability content}

For elective intellectual disability content, two medical schools provided content in both physical and mental health, two schools provided content in physical health only and two in mental health only. Elective content in the areas of paediatrics and professional development was offered at two schools and in general practice and sexual health at one school only. In no school was elective intellectual disability content offered in the areas of emergency medicine, women's health, men's health or other specialist areas of medicine (e.g. cardiovascular). The most frequently represented elective topic (6 participating schools) was interdisciplinary team work. The elective topics of clinical management skills, disability and health care systems, and human rights were each offered at four participating schools.

\section{Inclusive practice in intellectual disability education}

Compulsory intellectual disability units involving direct clinical contact with people with an intellectual disability were offered in only five medical schools (42\%). Such contact occurred within inpatient facilities, specialist clinics and community health settings, but not within disability accommodation, residential or educational settings (see Table 3). People with intellectual disability had been directly involved in the development or delivery of compulsory content in seven (58 \%) medical schools.

Elective intellectual disability content involving direct clinical contact with people with an intellectual disability was offered in two (17\%) medical schools. People with intellectual disability had been directly involved in the development or delivery of elective content in three (25\%) medical schools.

\section{Discussion}

\section{Overview of findings}

The audit revealed that all participating universities provided some compulsory intellectual disability content. However, the amount of content varied greatly between institutions, with the majority of responding institutions

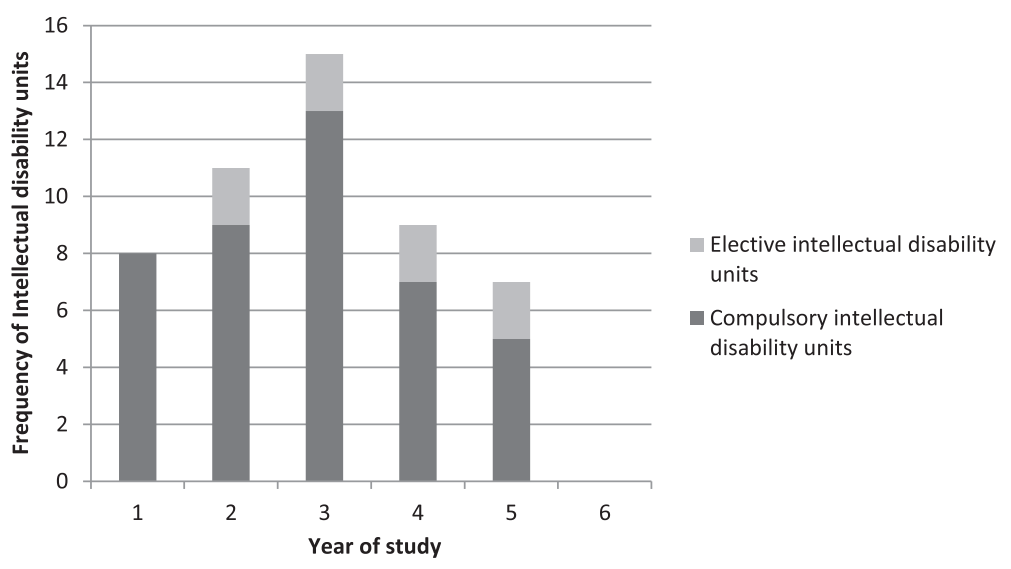

Fig. 3 Distribution of compulsory and elective intellectual disability content in medical courses 
Table 2 Discipline areas of medicine and specific topic areas covered within compulsory intellectual disability content

\begin{tabular}{|c|c|c|}
\hline & $\begin{array}{l}\text { Schools } \\
N\end{array}$ & $\begin{array}{l}\text { Units } \\
N\end{array}$ \\
\hline \multicolumn{3}{|l|}{ 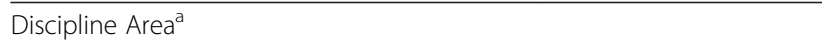 } \\
\hline Paediatrics & 9 & 11 \\
\hline Other $^{\mathrm{b}}$ & 6 & 7 \\
\hline General Practice & 4 & 7 \\
\hline Psychiatry & 3 & 5 \\
\hline Women's health & 2 & 2 \\
\hline Other specialist medicine ${ }^{c}$ & 1 & 8 \\
\hline Sexual health & 1 & 1 \\
\hline Emergency Medicine & 1 & 1 \\
\hline \multicolumn{3}{|l|}{ Topic Area $^{d}$} \\
\hline Clinical assessment skills & 9 & 27 \\
\hline Clinical management skills & 9 & 21 \\
\hline Ethics and legal issues & 8 & 20 \\
\hline Chronic and complex health issues & 8 & 17 \\
\hline Interdisciplinary team work & 8 & 12 \\
\hline Preventative health & 7 & 10 \\
\hline Disability and health care systems & 6 & 20 \\
\hline Human rights issues & 6 & 16 \\
\hline
\end{tabular}

${ }^{\mathrm{a} S i x}$ compulsory units were offered which covered two or more discipline areas

bIncludes: Disability studies, human development, professional development, societal aspects of intellectual disability

Includes: cardiovascular, endocrinology, genetics, head and neck, musculoskeletal, neurosciences, obstetrics, rehabilitation

${ }^{d} 28$ units were offered which covered two or more topic areas

N.B. Data from one school was unavailable

offering only a small amount of compulsory content. Overall, the time spent teaching compulsory and elective intellectual disability content was minimal, with the majority of schools offering less than six hours of compulsory teaching time across the entire course. Key topic areas of relevance to the health and well-being of people with intellectual disability were taught infrequently.

Table 3 Direct clinical contact environment offered in intellectual disability units

\begin{tabular}{|c|c|c|c|c|}
\hline \multirow[t]{2}{*}{ Clinical environment $^{\mathrm{a}}$} & \multicolumn{2}{|c|}{ Compulsory } & \multicolumn{2}{|l|}{ Elective } \\
\hline & SchoolsN & Units $N$ & SchoolsN & UnitsN \\
\hline Inpatient facility & 4 & 6 & 1 & 1 \\
\hline Specialist clinic & 4 & 5 & 1 & 3 \\
\hline Community health setting & 4 & 5 & 1 & 1 \\
\hline Disability service & 2 & 2 & 1 & 1 \\
\hline General practice & 1 & 1 & 2 & 2 \\
\hline School & 1 & 1 & 0 & 0 \\
\hline Group/family home & 0 & 0 & 2 & 2 \\
\hline
\end{tabular}

${ }^{a}$ Five compulsory units and four elective units included contact in two or more clinical environments
Despite what is known about psychiatric comorbidities [4] and primary health care needs [11] for people with intellectual disability, only a third of participating schools provided compulsory content in these areas. Similarly, despite this group's high unmet health needs $[3,7-10]$ and significant health inequalities [2, 43], only half of participating schools provided compulsory teaching relating to human rights issues, and disability and health care systems. Elective intellectual disability content in mental and/or physical health was only taught by half of the participating schools. Where provided, elective content was inconsistent in nature, and varied greatly in duration and number of student enrolments.

\section{Comparison with past audits}

The current findings are similar to that of Lennox and Diggens [28] who also found inconsistencies across medical curricula in the degree to which intellectual disability content was taught. They found that in some cases, teaching in intellectual disability was integrated across the curriculum, whilst in others, a small amount of content in limited areas was offered [28]. Their audit found that $70 \%$ of schools included compulsory teaching involving direct clinical contact with people with intellectual disability, a higher figure than obtained in the current audit. A positive finding, however, was that inclusive teaching practices in compulsory units have increased from $30 \%$ of schools in 1999 [28] to 58 \% (7 schools) in the current audit.

The inconsistencies found in intellectual disability teaching across universities also mirrored results from the 1994 UK audit [26]. Parallel to the current study's finding that clinical assessment and management skills were most often taught, with little focus on disability and health care systems, the majority of content taught in the UK medical schools was medical aspects of disability, with minimal teaching on support services. Medical graduates working in Malaysian public hospitals reported receiving most of their developmental disability education across paediatric and psychiatric curricula in comparison with other areas [27]. However we found the majority of compulsory units were offered in paediatrics, while only five units were in psychiatry.

\section{Current curricula in the context of research and policy}

This audit suggests that current teaching about intellectual disability in medical schools will not address the recognised lack of clinician confidence in this area [30,31], will not encourage the development of future workforce capacity in both mainstream and specialised intellectual disability healthcare, nor assist Australia to meet human rights [12] and anti-discrimination [15] requirements. Signatory states of the UNCRPD [12] have an obligation to meet the requirements outlined in the Convention, which means systemic change in the attitudes and values of 
practitioners, in health systems and in clinical skills including assessment, diagnosis, contextualised management and team work. This research suggests that Australia, a signatory state, does not have a coherent approach to the training of medical practitioners to meet the health needs of people with intellectual disability. Where teaching is provided, this has improved, but some areas such as in the provision of direct clinical contact with people with intellectual disability have seen regression.

Although inclusive practice in this area would fulfil human rights legislation $[12,15]$, implementation of inclusive approaches in medical schools was patchy. For example, although the involvement of people with intellectual disability in the development or delivery of compulsory content was noted for just over half of the participating medical schools, such involvement was far less likely for elective units, and direct clinical contact with people with intellectual disability occurred in a minority of schools. Inclusive teaching, particularly that which involves direct clinical contact with people with intellectual disability is of critical importance as it shapes attitudes, instils confidence and improves competence [32-34] in this clinical territory. Teaching initiatives in this area should therefore be required to include people with intellectual disability as a cornerstone in curriculum development, delivery and during clinical placements.

The clinical skills acquired while learning about intellectual disability, such as alternative communication methods, working in a multidisciplinary environment and involving families and carers can be used to improve clinical practice with other populations such as older adults and those with other disabilities. Such training would therefore be seen as an asset to current curricula, as it would equip students with higher level skills which could be employed in a variety of settings. It is clear there is a multifaceted case for including a greater focus on intellectual disability education in medical schools which in turn can lead to direct benefits for a population that has considerable unmet health needs.

Results from this study should be considered in the light of some key limitations. Engagement of medical schools in the audit may reflect a positive disposition and the presence of relevant content, which may have inflated figures relating to representation of intellectual disability content. Data collection relied heavily on email communication, which although aimed to reduce the burden on participating staff, may have increased fatigue and reduced engagement. As data were collected remotely, it was not possible to determine whether the information provided was comprehensive. Some of the questions were open-ended, so there was the possibility that respondents may have interpreted the questions in slightly different ways. For questions that were forced choice, the choices may not have covered all possible categories of response. Further, inconsistency in course structures and definitions of individual units of study made it difficult to directly compare the proportion of curriculum dedicated to specific intellectual disability teaching across schools.

In relation to the current findings, we recommend that medical schools respond to the evident health need and human rights legislation to ensure the training of medical professionals is comprehensive, principle based and consistent, with respect to the healthcare needs of children and adults with intellectual disability. There are plans to develop, evaluate and implement a national education framework and implementation toolkit for medical schools, which will provide up to date, evidence-based teaching materials and resources so universities can develop a comprehensive intellectual disability curriculum.

\section{Conclusions}

The current study was the first national audit of intellectual disability content in medical curricula to be conducted in Australia in 15 years. Our findings suggest that current intellectual disability content taught within medical training in Australia is highly variable and remains limited. Although more medical schools are now including some education in this area, there has been little movement towards a consistent and comprehensive medical curriculum in intellectual disability health, despite clear evidence of health disadvantage, recommendations from previous research $[26,28]$, significant changes in international and national human rights legislation and requirements for equity in service access $[12,15]$. Research has shown that inclusion of such content can improve attitudes and better prepare trainees to work with this population [32-34], provide skills which can enhance mainstream health services for people with intellectual disability $[35,36]$, and will likely encourage more graduates to specialise in this area [39]. There is therefore a well-defined and evidence-based need to improve medical training in this area, in order to build a workforce which is better equipped to meet the complex health needs of this population, and to improve equity of access to healthcare. With a greater emphasis on intellectual disability education, graduating medical practitioners will be better equipped to recognise and address current health disparities, and provide high quality healthcare in order to improve health outcomes for people with intellectual disability.

\section{Ethics approval and consent to participate}

Ethical approval for the study was obtained from the UNSW Australia Human Research Ethics Advisory Panel (Approval No. 2013-7-03). All participants read a participant information sheet before taking part and 
completion of the interview or survey was taken as implied consent.

\section{Consent for publication}

Not applicable.

\section{Availability of data and materials}

Please contact the first author for data and materials used in this study.

\section{Additional files}

Additional file 1: Phase 1: Interview Schedule- relating to the overal structure of the course. (PDF $172 \mathrm{~kb}$ )

Additional file 2: Phase 2: Survey Schedule- relating to specific unit of study. (PDF $182 \mathrm{~kb}$ )

\section{Abbreviations}

AMC: Australian Medical Council; MBBS: Bachelor of Medicine, Bachelor of Surgery; MD: Doctor of Medicine programme; UNCRPD: United Nations Convention on the Rights of Persons with Disabilities.

\section{Competing interests}

The authors declare that they have no competing interests.

\section{Authors' contributions}

JNT led the conceptualisation and design of the work, supervised the acquisition, analysis and interpretation of the data, and assisted with drafting and revising the manuscript. BR contributed to the acquisition, analysis and interpretation of the data, drafting and revising the manuscript. JT, JJT, SD, TI and NL contributed to the conceptualisation and design of the work interpretation of the data, and revising the manuscript. CE contributed to the interpretation of the data, and assisted with drafting and revising the manuscript. All authors read and approved the final manuscript and are accountable for the accuracy and integrity of all aspects of the work

\section{Acknowledgements}

The authors thank the New South Wales Government Family and Community Services, Department of Ageing, Disability and Homecare (ADHC) for supporting this project, the Australian Association of Developmental Disability Medicine, Medical Deans Australia and New Zealand, the Royal Australian College of General Practitioners, and the Royal Australian and New Zealand College of Psychiatrists for their endorsement of the survey and the participating medical schools. JNT receives funding from the National Health and Medical Research Council; UNSW Australia; South Eastern Sydney Local Health District, Mental Health and Drug \& Alcohol Office and MH-Kids NSW Ministry of Health; NSW Government Family and Community Services, Ageing, Disability and Home Care; Mental Health Commission of NSW, and the NSW Ombudsman. BR is funded by the NSW Government Family and Community Services, Department of Ageing, Disability and Home Care and the School of Psychiatry, UNSW Australia. JT is funded by salary from the Victorian Department of Health and Human Services. JJT receives income from Melbourne Health; St Vincent's Health; the Victorian Govern ment for work on the Mental Health Tribunal, the Forensic Leave Panel, and the Mental Health Complaints Commission; TazReach; and from private practice. SD is funded by salary from The University of Sydney. Tl is funded by salary from La Trobe University. CE is funded by the School of Psychiatry, UNSW Australia. NL is funded by salary from The University of Queensland.

\section{Funding}

This research was funded by the NSW Government Family and Community Services, Department of Ageing, Disability and Home Care. The funding body did not have any role in the design, collection, analysis, and interpretation of data, in the writing of the manuscript or decision to submit the manuscript for publication.

\section{Author details}

'Department of Developmental Disability Neuropsychiatry (3DN), UNSW Australia, 34 Botany Street, Randwick, NSW 2052, Australia. ${ }^{2}$ Centre for Developmental Disability Health Victoria (CDDHV), Monash Health, 122 Thomas Street, Dandenong, VIC 3175, , Australia. ${ }^{3}$ Faculty of Medicine, Nursing and Health Sciences, Monash University VIC, 3800, Australia. ${ }^{4}$ Centre for Disability Studies, Sydney Medical School, The University of Sydney, Level 1, Medical Foundation Building, 92-94 Parramatta Road, Camperdown, NSW 2050, Australia. ${ }^{5}$ La Trobe Rural Health School, La Trobe University, PO Box 199, Bendigo, VIC 3552, Australia. ${ }^{6}$ Queensland Centre for Intellectual and Developmental Disability (QCIDD), Mater Research Institute, The University of Queensland, Level 2 Aubigny Place, Mater Hospitals, South Brisbane, QLD 4101, Australia.

Received: 29 September 2015 Accepted: 2 April 2016 Published online: 11 April 2016

\section{References}

1. Maulik PK, Mascarenhas MN, Mathers CD, Dua T, Saxena S. Prevalence of intellectual disability: a meta-analysis of population-based studies. Res Dev Disabil. 2011;32:419-36.

2. Emerson E, Baines S, Allerton L, Welch V. Health inequalities and people with learning disabilities in the UK: 2012. Durham: Improving Health \& Lives: Learning Disabilities Observatory; 2012.

3. Beange $H$, McElduff A, Baker W. Medical disorders of adults with mental retardation: A population study. Am J Ment Retard. 1995:99:595-604.

4. Einfeld SL, Piccinin AM, Mackinnon A, Hofer SM, Taffe J, Gray KM, et al. Psychopathology in young people with intellectual disability. JAMA. 2006. 296:1981-9. doi:10.1001/jama.296.16.1981.

5. Heslop P, Blair PS, Fleming P, Hoghton M, Marriott A, Russ L. The Confidential Inquiry into premature deaths of people with intellectual disabilities in the UK: a population-based study. Lancet. 2014;383:889-95. doi:10.1016/S0140-6736(13)62026-7.

6. Tyrer F, McGrother C. Cause-specific mortality and death certificate reporting in adults with moderate to profound intellectual disability. Intellect Disabil Res. 2009;53:898-904. doi:10.1111/j.1365-2788.2009.01201.x.

7. Lennox N, Bain C, Rey-Conde T, Purdie D, Bush R, Pandeya N. Effects of a comprehensive health assessment programme for Australian adults with intellectual disability: a cluster randomized trial. Int J Epidemiol. 2007:36:139-46.

8. Lennox N, Bain C, Rey-Conde T, Taylor M, Boyle FM, Purdie DM, et al. Cluster Randomized-Controlled Trial of Interventions to Improve Health for Adults with Intellectual Disability Who Live in Private Dwellings. J Appl Res Intellect Disabil. 2010;23:303-11. doi:10.1111/j.1468-3148.2009.00533.x.

9. Robertson J, Roberts H, Emerson E, Turner S, Greig R. The impact of health checks for people with intellectual disabilities: a systematic review of evidence. J Intellect Disabil Res. 2011;55:1009-19. doi:10.1111/j.1365-2788.2011.01436.x.

10. Sutherland G, Couch MA, lacono T. Health issues for adults with developmental disability. Res Dev Disabil. 2002:23:422-45. doi:10.1016/ S0891-4222(02)00143-9.

11. lacono T, Davis R. The experiences of people with developmental disability in emergency departments and hospital wards. Res Dev Disabil. 2003;24:247-64. doi:10.1186/s12913-014-0505-5.

12. UN General Assembly. United Nations Convention on the Rights of Persons with Disabilities, 13 December 2006, A/RES/61/106, Annex I. New York: UN General Assembly; 2006

13. Equality Act 2010, Government of United Kingdom. The National Archives http://www.legislation.gov.uk/ukpga/2010/15/contents. Accessed 5 Apr 2016

14. Americans With Disabilities Act of 1990, Stat. Statute 328 (1990). United States Department of Justice Civil Rights Division. http://www.ada.gov/ pubs/adastatute08.pdf. Accessed 5 Apr 2016.

15. Commonwealth Government Australia. Disability Discrimination Act Canberra: Attorney-General's Department; 1992.

16. The Faculty for People with Intellectual Disabilities, Division of Clinical Psychology, British Psychological Society. http://www.bps.org.uk/networksand-communities/member-microsite/dcp-faculty-people-intellectualdisabilities. Accessed 16 Jul 2015.

17. Faculty of Psychiatry of Intellectual Disability, Royal College of Psychiatrists http://www.rcpsych.ac.uk/workinpsychiatry/faculties/intellectualdisability. aspx. Accessed 16 Jul 2015

18. The Australian Association of Developmental Disability Medicine (AADDM). http://ausaddm.wordpress.com/home/[Accessed. 16 Jul 2015. 
19. Neurodevelopmental and Behavioural Paediatric Society of Australasia (NBPSA). http://nbpsa.org/. Accessed 16 Jul 2015.

20. The Royal Australasian College of Physicians (RACP) Paediatrics and Child Health Division. http://www.racp.edu.au/advocacy/division-faculty-andchapterpriorities/paediatrics-and-child-health-division. Accessed 5 Apr 2016.

21. The Royal Australian \& New Zealand College of Psychiatrists (RANZCP) Special Interest Group in the Psychiatry of Intellectual and Developmental Disabilities. http://www.ranzcp.org/Membership/Subspecialty-groups/InterestGroups/Intellectual-Developmental-Disabilities.aspx. Accessed 17 Jul 2015.

22. Commonwealth of Australia. 2010-2020 National Disability Strategy: An initiative of the Council of Australian Governments. Commonwealth of Australia, 2011.

23. National Disability Insurance Scheme (NDIS). http://www.ndis.gov.au/. Accessed 8 Jun 2015.

24. NHS Direct Payments and Personal Budgets. http://www.nhs.uk/Conditions/ social-care-and-support-guide/Pages/direct-payments-personal-budgets. aspx. Accessed 3 Jul 2015.

25. Spalding K, Watkins JR, Williams AP. Self Managed Care Programs in Canada: A Report to Health Canada. 2006

26. Kahtan S, Inman C, Haines A, Holland P. Teaching disability and rehabilitation to medical students. Med Educ. 1994;28:386-93. doi:10.1111/j. 1365-2923.1994.tb02549.x.

27. Moyle $\mathrm{L}$, lacono T, Liddell M. Knowledge and perceptions of newly graduated medical practitioners in Malaysia of their role in medical care of people with developmental disabilities. J Policy Pract Intellect Disabil. 2010;7:85-95.

28. Lennox N, Diggens J. Medical education and intellectual disability: A survey of Australian medical schools. J Intellect Dev Disabil. 1999;24:333-40. doi:10.1080/13668259900034091.

29. Lennox N, Diggens J. Knowledge, skills and attitudes: Medical schools' coverage of an ideal curriculum on intellectual disability. J Intellect Dev Disabil. 1999;24:341-7. doi:10.1080/13668259900034101.

30. Sahin H, Akyol AD. Evaluation of nursing and medical students' attitudes towards people with disabilities. J Clin Nurs. 2010;19:2271-9. doi:10.1111/j. 1365-2702.2009.03088.x.

31. Tervo RC, Palmer G. Health professional student attitudes towards people with disability. Clin Rehabil. 2004;18:908-15. doi:10.1191/0269215504cr820oa.

32. Lennox N. General practice registrars' care of people with intellectual disabilities. J Intellect Dev Disabil. 2000;25:69-77.

33. Hall I, Hollins S. Changing medical students' attitudes to learning disability. Psychiatr Bull. 1996;20:429-30.

34. Tracy J, lacono T. People with developmental disabilities teaching medical students-Does it make a difference? J Intellect Dev Disabil. 2008;33:345-8.

35. Costello $\mathrm{H}$, Bouras $\mathrm{N}$, Davis $\mathrm{H}$. The role of training in improving community care staff awareness of mental health problems in people with intellectual disabilities. J Appl Res Intellect Disabil. 2007;20:228-35. doi:10.1111/j.14683148.2006.00320.x

36. Torr J, Lennox N, Cooper S-A, Rey-Conde T, Ware RS, Galea J, et al. Psychiatric care of adults with intellectual disabilities: changing perceptions over a decade. Aust N Z J Psychiatry. 2008;42:890-7. doi:10.1080/00048670802345474.

37. Campbell FK. Medical education and disability studies. J Med Humanit. 2009;30:221-35. doi:10.1007/s10912-009-9088-2.

38. Piachaud J. Teaching learning disability to undergraduate medical students. Adv Psychiatr Treat. 2002;8:334-41. doi:10.1192/apt.8.5.334.

39. Happell B. Moving in circles: A brief history of reports and inquiries relating to mental health content in undergraduate nursing curricula. Nurse Educ Today. 2010;30:643-8. doi:10.1016/j.nedt.2009.12.018.

40. Department of Developmental Disability Neuropsychiatry. Accessible Mental Health Services for People with an Intellectual Disability: A Guide for Providers. Department of Developmental Disability Neuropsychiatry; 2014. https://3dn. unsw.edu.au/the-guide. Accessed 5 Apr 2016. ISBN 978-0-7334-3431-0.

41. Australian Medical Council Limited. Standards for Assessment and Accreditation of Primary Medical Programs by the Australian Medical Council. 2012

42. Liaison Committee on Medical Education. Functions and Structure of a Medical School: Standards for Accreditation of Medical Education Programs Leading to the M.D. Degree. Liaison Committee on Medical Education 2015. http://lcme.org/publications/. Accessed 5 Apr 2016.

43. Bittles AH, Petterson BA, Sullivan SG, Hussain R, Glasson EJ, Montgomery PD. The influence of intellectual disability on life expectancy. J Gerontol A Biol Sci Med Sci. 2002;57:M470-2

\section{Submit your next manuscript to BioMed Central and we will help you at every step:}

- We accept pre-submission inquiries

- Our selector tool helps you to find the most relevant journal

- We provide round the clock customer support

- Convenient online submission

- Thorough peer review

- Inclusion in PubMed and all major indexing services

- Maximum visibility for your research

Submit your manuscript at www.biomedcentral.com/submit 